\title{
Comparison of Initial Clinical Presentations between Primary Hyperparathyroidism Patients from New Brunswick and Changsha
}

\author{
Lingqiong Meng $\mathbb{D},{ }^{1,2}$ Shuying Liu, ${ }^{3}$ Aseel Al-Dayyeni, ${ }^{1,4}$ Zhifeng Sheng $\mathbb{D},{ }^{3,5,6}$ \\ Zhiguang Zhou $\mathbb{D},{ }^{5,6}$ and Xiangbing Wang $\mathbb{1}^{1}$ \\ ${ }^{1}$ Division of Endocrinology and Metabolism, Rutgers-RWJMS, New Brunswick, NJ 08901, USA \\ ${ }^{2}$ Graduate School of Biomedical Science, Rutgers University, Piscataway, NJ 08854, USA \\ ${ }^{3}$ Department of Metabolism and Endocrinology, The Second Xiangya Hospital, Central South University, Changsha, \\ Hunan 410011, China \\ ${ }^{4}$ Physiology and Integrative Biology, Rutgers University, New Brunswick, NJ 08901, USA \\ ${ }^{5}$ National Clinical Research Center for Metabolic Diseases, The Second Xiangya Hospital, Central South University, Changsha, \\ Hunan 410011, China \\ ${ }^{6}$ Institution of Metabolism and Endocrinology, The Second Xiangya Hospital, Central South University, Changsha, \\ Hunan 410011, China
}

Correspondence should be addressed to Zhifeng Sheng; szf1976@hotmail.com and Xiangbing Wang; wangx9@rwjms.rutgers.edu Received 2 May 2018; Revised 27 July 2018; Accepted 28 August 2018; Published 18 September 2018

Academic Editor: Giorgio Borretta

Copyright (c) 2018 Lingqiong Meng et al. This is an open access article distributed under the Creative Commons Attribution License, which permits unrestricted use, distribution, and reproduction in any medium, provided the original work is properly cited.

\begin{abstract}
Purpose. To compare the initial clinical features, laboratory values, and bone mineral density among patients with primary hyperparathyroidism (PHPT) in Changsha (China) and New Brunswick (USA). Methods. In this retrospective study, we reviewed 169 PHPT patients who presented at Robert Wood Johnson University Hospital and 133 PHPT patients who presented at the Second Xiangya Hospital of Central South University in the same time period. The following characteristics were compared between the groups: age, gender, BMI, serum calcium, alkaline phosphatase (AKP), albumin, intact PTH (iPTH), 25-hydroxyvitamin D (25 (OH) D), fasting blood glucose levels, and bone mineral density (BMD). All these parameters were also compared according to gender and menopausal status. iPTH associations were also assessed along with several other parameters. Results. PHPT patients from Changsha had higher serum calcium, iPTH, and AKP levels but lower $25(\mathrm{OH}) \mathrm{D}$ levels than the patients from New Brunswick $(p<0.05)$. Patients in Changsha had lower $T$-scores and $Z$-scores in both the lumbar spine and hip regions than those in New Brunswick $(p<0.05)$. Patients in New Brunswick had lower percentages of parathyroid adenoma and kidney stones. Serum iPTH level was positively correlated with serum calcium and serum AKP levels in both Changsha and New Brunswick $(p<0.05)$. Conclusions. There are distinct biochemical and clinical differences between patients with PHPT in China and the United States. Our study revealed that Asian PHPT patients from Changsha presented more severe PHPT profiles, lower bone mineral density, and higher incidence of renal stones.
\end{abstract}

\section{Introduction}

The use of multichannel chemistry screening tests in the United States and other Western countries since the 1970s has made primary hyperparathyroidism (PHPT) a more commonly recognized endocrine disease, and it has shifted from being a classically symptomatic disorder to an asymptomatic one $[1,2]$. Nowadays, most patients with PHPT in the US are asymptomatic as compared with their counterparts in developing Asian countries, such as India and China, who are still characterized with distinct clinical manifestations and severe biochemical markers [3]. Currently, 
few data are available on PHPT comparisons between China and the USA.

Although a recent study showed a mild increase in asymptomatic PHPT patients in Shanghai, there were still major differences in clinical presentations between Shanghai (China) and New York City (USA). The data suggested that geographical locations, ethnicities, and other factors may contribute to the overt differences in clinical and biochemical manifestations [4]. However, the PHPT patients from the two cities were from different time periods: Shanghai (2001-2010) and New York (2009-2013). The PHPT profiles of China might have changed, as the use of multichannel chemistry tests and ultrasound examination of the neck has recently become widely available in China. We therefore compared the initial presentation of patients with PHPT from Changsha, China, and New Brunswick, USA, in the same time period. The comparison of clinical characteristics of PHPT from different geographical locations or ethnicities from the same time periods may help clinicians do a better job diagnosing and managing PHPT patients from different ethnic backgrounds. Our current study may also provide clues for understanding the role of genetic, environmental, and nutritional factors in the development of PHPT.

\section{Methods}

This is a chart review and retrospective study. Medical records of PHPT patients at the Divisions of Endocrinology and General Surgery at Robert Wood Johnson University Hospital (New Brunswick, NJ) and the Division of Endocrinology at the Second Xiangya Hospital of Central South University (Changsha, China) from 2010 to 2016 were reviewed separately and identified. The data collection was finished by trained endocrinologists in both countries. The initial diagnoses of primary hyperparathyroidism were diagnosed through (1) confirmed hypercalcemia (calcium $>10.4 \mathrm{mg}$ / $\mathrm{dL}$ ) and (2) elevated intact PTH levels (iPTH $>65 \mathrm{pg} / \mathrm{mL}$ ). Patients diagnosed with multiple endocrine neoplasm (MEN) and parathyroid carcinoma were excluded. The protocols were approved by the Institutional Review Boards of Rutgers University (New Brunswick, USA) and the Second Xiangya Hospital (Changsha, China).

Age, gender, menopausal status, BMI, level of serum calcium, iPTH, $25(\mathrm{OH}) \mathrm{D}$, albumin, AKP, creatinine, and fasting blood glucose levels were recorded. Albumincorrected serum calcium was calculated by the following formula: corrected calcium $=$ serum calcium $+0.8 \times(4-$ serum albumin). All patients from two cities were queried for the history of kidney stones. Past medical history of renal stones was expressed as a percentage. For patients who underwent parathyroidectomy (158 and 92 PHPT patients in New Brunswick and Changsha, respectively), adenoma or hyperplasia was determined by a pathologist according to pathological features of parathyroid glands [5] and confirmed by another pathologist. We also collected lumbar spine and total hip BMD using dual-energy X-ray absorptiometry (DXA) with the GE Lunar Prodigy Advance $(\mathrm{CV} \leq 1 \%, T$-score and $Z$-score) in patients from both cities. iPTH associations were also assessed along with several other parameters.
Serum calcium, AKP, serum creatinine, serum albumin, and fasting blood glucose were measured by cobas e analyzers using standard enzymatic and colorimetric assay protocols in both cities. Serum iPTH levels were measured by cobas e analyzers with the normal range 15-65 pg/mL, and serum $25(\mathrm{OH})$ D levels were assessed using cobas automated radioimmunoassay analyzers with the normal range $30-80 \mathrm{ng} / \mathrm{mL}$ in New Brunswick. Serum iPTH levels were measured by Elecsys analyzers with the normal range $14-63 \mathrm{pg} / \mathrm{mL}$, and serum $25(\mathrm{OH}) \mathrm{D}$ levels were measured by Siemens analyzers with the normal range $30-100 \mathrm{ng} / \mathrm{mL}$ in Changsha.

2.1. Statistical Analysis. The results that were normally distributed were expressed as mean $\pm \mathrm{SD}$, while those without normal distribution were expressed as median (range). Normal distributions between groups were compared with the Student $t$-test. Nonnormal distributions between groups were compared with the Wilcoxon rank sum test. The prevalence rates between groups were compared using Chisquare tests for significance. Correlation coefficients, linear regression, and logistic regression were used to assess relationships. Two-sided $p$ values of $<0.05$ were selected as the significance level.

\section{Results}

We included 169 PHPT patients (130 females and 39 males) from Robert Wood Johnson University Hospital and 133 PHPT patients (87 females and 44 males) from the Second Xiangya Hospital. Two PHPT patients from Changsha were diagnosed with parathyroid cancer, while no parathyroid cancer was found in the New Brunswick sample. We excluded parathyroid cancer patients for better comparison. PHPT patients from New Jersey included 138 Caucasian, 13 Black, 10 Hispanic, and 8 Asian patients. Table 1 shows the clinical characteristics and biochemical values of PHPT patients from both cities. Compared to PHPT patients from New Brunswick, PHPT patients from Changsha were younger, with lower BMI, higher serum calcium, iPTH, and AKP levels, and lower $25(\mathrm{OH}) \mathrm{D}$ levels $(p<0.05)$. Fasting glucose was also higher in New Brunswick PHPT patients than in those patients from Changsha $(p<0.05$, Table 1$)$. Compared to PHPT patients from New Brunswick, PHPT patients from Changsha had more kidney stones at the initial evaluation $(p<0.001$, Table 1). For patients that had parathyroidectomy, pathology reports showed that $92 \%$ of PHPT patients from Changsha had parathyroid adenoma while only $48 \%$ of PHPT patients from New Brunswick had parathyroid adenoma (Table $1, p<0.001$ ).

There are 34\% male PHPT patients and 25\% premenopausal female PHPT patients from Changsha while there are only $25 \%$ male PHPT patients and $17 \%$ premenopausal PHPT patients from New Brunswick (Table 2). Males and premenopausal females have higher calcium and PTH levels but lower $25(\mathrm{OH})$ D levels than the postmenopausal females in both cities. Compared to PHPT patients from New Brunswick, all PHPT patients (male and pre- or 
TABle 1: Comparison of clinical features of PHPT patients in New Brunswick and Changsha from 2010 to 2016.

\begin{tabular}{|c|c|c|c|c|c|}
\hline \multirow{2}{*}{ Clinical features } & \multicolumn{2}{|c|}{ Changsha } & \multicolumn{2}{|c|}{ New Brunswick } & \multirow{2}{*}{$p$ value } \\
\hline & $n=131$ & Normal range & $n=169$ & Normal range & \\
\hline Age (years) & $52.4 \pm 15.4$ & & $58.4 \pm 12.5$ & & $<0.01$ \\
\hline Female (\%) & $66 \%(87 / 131)$ & & $77 \%(130 / 169)$ & & $<0.05$ \\
\hline Duration (years) & $5.8 \pm 7.7$ & & $4.4 \pm 6.4$ & & 0.7 \\
\hline BMI $\left(\mathrm{kg} / \mathrm{m}^{2}\right)$ & $21.5 \pm 3.9$ & & $29.3 \pm 6.5$ & & $<0.001$ \\
\hline $\mathrm{Ca}(\mathrm{mg} / \mathrm{dL})$ & $13.1 \pm 2.3$ & $8.4-10.1$ & $11.1 \pm 0.6$ & $8.6-10.4$ & $<0.001$ \\
\hline Serum PTH $(\mathrm{pg} / \mathrm{mL})$ & $676.4 \pm 564.7$ & $14.0-63.0$ & $138.7 \pm 99.7$ & $15.0-65.0$ & $<0.001$ \\
\hline $25(\mathrm{OH}) \mathrm{D}(\mathrm{ng} / \mathrm{mL})$ & $14.2 \pm 8.1$ & $30.0-100.0$ & $29.5 \pm 11.0$ & $30.0-80.0$ & $<0.001$ \\
\hline Albumin (g/dL) & $3.9 \pm 0.6$ & $4.0-5.5$ & $4.3 \pm 0.5$ & $3.5-5.5$ & $<0.001$ \\
\hline Corrected $\mathrm{Ca}(\mathrm{mg} / \mathrm{dL})$ & $13.2 \pm 2.5$ & & $10.8 \pm 0.7$ & & $<0.001$ \\
\hline $\mathrm{AKP}(\mathrm{U} / \mathrm{L})$ & $383.7 \pm 645.9$ & $50.0-135.0$ & $86.0 \pm 30.4$ & $45.0-115.0$ & $<0.001$ \\
\hline Glucose (mg/dL) & $92.7 \pm 23.2$ & $70.0-110.0$ & $99.7 \pm 19.6$ & $65.0-99.0$ & $<0.001$ \\
\hline Creatinine (mg/dL) & $1.1 \pm 0.7$ & $0.5-1.5$ & $0.9 \pm 0.3$ & $0.5-1.2$ & 0.7 \\
\hline Kidney stone (\%) & $62 \%(81 / 131)$ & & $31 \%(52 / 169)$ & & $<0.001$ \\
\hline Adenoma (\%) & $92 \%(85 / 92)$ & & $48 \%(77 / 159)$ & & $<0.001$ \\
\hline
\end{tabular}

PTH: parathyroid hormone; BMI: body mass index; Ca: serum calcium; 25 (OH) D: 25-hydroxyvitamin D; AKP: alkaline phosphatase.

TABle 2: Comparison between male and pre- and postmenopausal female PHPT patients from New Brunswick and Changsha.

\begin{tabular}{|c|c|c|c|c|c|c|}
\hline Clinical features & $\begin{array}{c}\text { Male }(n=39) \\
\text { NB }\end{array}$ & $\begin{array}{c}\text { Male }(n=44) \\
\text { CS }\end{array}$ & $\begin{array}{c}\text { Pre-F }(n=28) \\
\text { NB }\end{array}$ & $\begin{array}{c}\text { Pre-F }(n=33) \\
\text { CS }\end{array}$ & $\begin{array}{c}\text { Post-F }(n=102) \\
\text { NB }\end{array}$ & $\begin{array}{c}\text { Post-F }(n=54) \\
\text { CS }\end{array}$ \\
\hline Age (years) & $59.1 \pm 10.7^{\mathrm{a}, \mathrm{b}, \mathrm{e}}$ & $49.3 \pm 16.6^{\mathrm{c}, \mathrm{d}}$ & $39.4 \pm 8.7^{\mathrm{b}}$ & $38.7 \pm 9.7^{\mathrm{d}}$ & $63.3 \pm 8.6$ & $63.2 \pm 7.6$ \\
\hline Duration (years) & $4.6 \pm 6.3$ & $6.7 \pm 8.1$ & $3.1 \pm 3.2$ & $4.3 \pm 6.0$ & $4.7 \pm 7.0$ & $6.0 \pm 8.2$ \\
\hline BMI $\left(\mathrm{kg} / \mathrm{m}^{2}\right)$ & $30.4 \pm 4.9^{\mathrm{a}, \mathrm{e}}$ & $21.7 \pm 3.2$ & $27.4 \pm 6.7^{\mathrm{c}}$ & $19.8 \pm 4.8^{\mathrm{d}}$ & $29.3 \pm 7.0^{\mathrm{d}}$ & $22.3 \pm 3.8$ \\
\hline Serum $\mathrm{Ca}(\mathrm{mg} / \mathrm{dL})$ & $11.2 \pm 0.6^{\mathrm{e}}$ & $13.4 \pm 2.2$ & $11.2 \pm 0.6^{\mathrm{c}}$ & $13.4 \pm 2.7$ & $11.0 \pm 0.5^{\mathrm{d}}$ & $12.8 \pm 2.2$ \\
\hline Serum PTH $(\mathrm{pg} / \mathrm{mL})$ & $157.7 \pm 125.0^{\mathrm{b}, \mathrm{e}}$ & $788.4 \pm 519.5^{\mathrm{d}}$ & $170.3 \pm 156.5^{\mathrm{b} . c}$ & $801.9 \pm 637.6^{\mathrm{d}}$ & $122.8 \pm 58.5^{\mathrm{d}}$ & $503.2 \pm 516.7$ \\
\hline $25(\mathrm{OH}) \mathrm{D}(\mathrm{ng} / \mathrm{mL})$ & $27.7 \pm 9.3^{\mathrm{e}}$ & $14.3 \pm 8.7$ & $26.7 \pm 12.7^{\mathrm{c}}$ & $13.9 \pm 7.3$ & $30.8 \pm 10.9^{\mathrm{d}}$ & $14.2 \pm 8.3$ \\
\hline Albumin (g/dL) & $4.4 \pm 0.6^{\mathrm{e}}$ & $3.8 \pm 0.5$ & $4.4 \pm 0.3^{\mathrm{c}}$ & $4.0 \pm 0.5$ & $4.3 \pm 0.4^{\mathrm{d}}$ & $3.8 \pm 0.7$ \\
\hline $\mathrm{AKP}(\mathrm{U} / \mathrm{L})$ & $88.9 \pm 33.2^{\mathrm{e}}$ & $384.1 \pm 564.8^{\mathrm{d}}$ & $92.3 \pm 42.2^{\mathrm{c}}$ & $794.0 \pm 1034.3^{\mathrm{d}}$ & $83.2 \pm 25.1^{\mathrm{d}}$ & $166.1 \pm 234.2$ \\
\hline Glucose (mg/dL) & $102.8 \pm 20.8^{\mathrm{e}}$ & $94.9 \pm 27.1$ & $98.3 \pm 21.6$ & $87.5 \pm 19.7$ & $98.8 \pm 18.5$ & $94.1 \pm 21.5$ \\
\hline Creatinine $(\mathrm{mg} / \mathrm{dL})$ & $1.09 \pm 0.3^{\mathrm{a}, \mathrm{b}}$ & $1.3 \pm 0.8^{\mathrm{c}, \mathrm{d}}$ & $0.6 \pm 0.1^{\mathrm{b}, \mathrm{c}}$ & $0.9 \pm 0.6$ & $0.8 \pm 0.2$ & $0.9 \pm 0.4$ \\
\hline Kidney stone (\%) & $44 \%(17 / 39)^{\mathrm{a}, \mathrm{b}, \mathrm{e}}$ & $77 \%(34 / 44)^{\mathrm{c}, \mathrm{d}}$ & $29 \%(8 / 28)^{\mathrm{c}}$ & $52 \%(17 / 33)$ & $26 \%(27 / 102)^{\mathrm{d}}$ & $55.6 \%(30 / 54)$ \\
\hline Total hip BMD ( $T$-score) & $-0.697 \pm 0.927^{\mathrm{a}, \mathrm{b}, \mathrm{e}}$ & $-2.532 \pm 1.190$ & $-0.167 \pm 0.823^{\mathrm{b}, \mathrm{c}}$ & $-2.594 \pm 1.557$ & $-1.075 \pm 1.100^{\mathrm{d}}$ & $-2.439 \pm 1.060$ \\
\hline L1-4 BMD ( $T$-score $)$ & $-0.295 \pm 1.492^{\mathrm{b}, \mathrm{e}}$ & $-2.536 \pm 1.497^{\mathrm{d}}$ & $-0.515 \pm 1.203^{\mathrm{b}, \mathrm{c}}$ & $-2.529 \pm 1.240^{\mathrm{d}}$ & $-0.839 \pm 1.501^{\mathrm{d}}$ & $-2.930 \pm 0.968$ \\
\hline
\end{tabular}

Pre-F: premenopausal women; Post-F: postmenopausal women; NB: New Brunswick; CS: Changsha; BMI: body mass index; AKP: alkaline phosphatase; Ca: calcium; $25(\mathrm{OH})$ D: 25 -hydroxyvitamin D. Significant level $p<0.05$. ${ }^{\mathrm{a}}$ Significant vs. Pre-F in NB. ${ }^{\mathrm{b}}$ Significant vs. Post-F in NB. ${ }^{\mathrm{c}}$ Significant vs. Pre-F in CS. ${ }^{\mathrm{d}}$ Significant vs. Post-F in CS. ${ }^{\mathrm{e}}$ Significant vs. male in CS.

postmenopausal female) from Changsha had higher serum calcium, iPTH, and AKP levels and lower $25(\mathrm{OH}) \mathrm{D}$ levels. All PHPT patients from Changsha also had lower $T$-scores in the lumbar spine or hip region (Tables 2 and 3 ).

The iPTH levels were negatively correlated with BMI and serum $25(\mathrm{OH})$ D levels in patients from Changsha and New Brunswick (Table 4, $p<0.05$ ). iPTH levels were positively correlated with serum calcium and AKP levels in patients from Changsha and New Brunswick (Table 4, $p<0.05$ ). After a multivariate regression analysis, iPTH remained significantly correlated with serum calcium and AKP levels in patients from both cities $(p<0.05)$ (Table 4$)$.

\section{Discussion}

The understanding of PHPT has been changing substantially over the last few decades [2]. By comparing the clinical presentation of PHPT patients from New Brunswick (USA) and Changsha (China) over the same time period, we found that biochemical and clinical differences between the two countries still exist. Our current data showed that PHPT patients from Changsha have higher serum calcium, iPTH, and AKP levels, lower $25(\mathrm{OH})$ D levels, and lower bone mineral density, suggesting that they have more severe PHPT at the initial presentation. 
TABLE 3: Comparison of BMD of PHPT patients in New Brunswick and Changsha from 2010 to 2016.

\begin{tabular}{lccr}
\hline Clinical features & Changsha $(n=131)$ & New Brunswick $(n=169)$ & $p$ value \\
\hline Total hip BMD $\left(\mathrm{g} / \mathrm{cm}^{2}\right)$ & $0.623 \pm 0.150$ & $0.900 \pm 0.150$ & $<0.001$ \\
Total hip BMD $(T$-score $)$ & $-2.507 \pm 1.212$ & $-0.839 \pm 1.070$ & $<0.001$ \\
Total hip BMD $(Z$-score $)$ & $-1.572 \pm 1.486$ & $-0.195 \pm 0.978$ & $<0.001$ \\
L1-4 BMD $\left(\mathrm{g} / \mathrm{cm}^{2}\right)$ & $0.713 \pm 0.149$ & $1.077 \pm 0.195$ & $<0.001$ \\
L1-4 BMD $(T$-score $)$ & $-2.691 \pm 1.256$ & $-0.659 \pm 1.466$ & $<0.001$ \\
L1-4 BMD $(Z$-score $)$ & $-1.608 \pm 1.532$ & $0.127 \pm 1.434$ & $<0.001$ \\
\hline
\end{tabular}

BMD: bone mineral density.

TABLE 4: Simple linear regression and multiple linear regression of relation adjusted for age and BMI (partial correlation coefficients) between serum iPTH and other variables in patients with primary hyperparathyroidism in Changsha and New Brunswick and all patients in the two cities.

\begin{tabular}{|c|c|c|c|c|c|c|}
\hline \multirow[b]{2}{*}{ Serum PTH (pg/mL) } & \multicolumn{3}{|c|}{ Simple linear regression } & \multicolumn{3}{|c|}{ Multiple linear regression } \\
\hline & $\begin{array}{l}\text { Changsha } \\
(n=131)\end{array}$ & $\begin{array}{c}\text { New Brunswick } \\
\quad(n=169)\end{array}$ & $\begin{array}{c}\text { Total } \\
(n=300)\end{array}$ & $\begin{array}{c}\text { Changsha } \\
(n=131)\end{array}$ & $\begin{array}{c}\text { New Brunswick } \\
\quad(n=169)\end{array}$ & $\begin{array}{c}\text { Total } \\
(n=300)\end{array}$ \\
\hline Age (years) & $-0.29^{\mathrm{b}}$ & 0.03 & $-0.21^{\mathrm{b}}$ & -0.01 & 0.04 & -0.04 \\
\hline Duration (years) & 0.03 & -0.03 & 0.01 & 0.08 & -0.01 & 0.01 \\
\hline BMI $\left(\mathrm{kg} / \mathrm{m}^{2}\right)$ & $-0.28^{\mathrm{b}}$ & 0.02 & $-0.45^{\mathrm{a}}$ & -0.14 & 0.01 & -0.06 \\
\hline $\mathrm{Ca}(\mathrm{mg} / \mathrm{dL})$ & $0.43^{\mathrm{a}}$ & $0.13^{\mathrm{c}}$ & $0.54^{\mathrm{a}}$ & $0.44^{\mathrm{a}}$ & $0.23^{\mathrm{b}}$ & $0.50^{\mathrm{a}}$ \\
\hline $25(\mathrm{OH}) \mathrm{D}(\mathrm{ng} / \mathrm{mL})$ & $-0.25^{\mathrm{c}}$ & $-0.20^{\mathrm{c}}$ & $-0.53^{\mathrm{a}}$ & -0.15 & -0.14 & $-0.11^{\mathrm{c}}$ \\
\hline AKP (U/L) & $0.69^{\mathrm{a}}$ & $0.23^{\mathrm{b}}$ & $0.60^{\mathrm{a}}$ & $0.59^{\mathrm{a}}$ & $0.34^{\mathrm{a}}$ & $0.63^{\mathrm{a}}$ \\
\hline $\mathrm{Cr}(\mathrm{mg} / \mathrm{dL})$ & $0.22^{\mathrm{c}}$ & 0.01 & 0.11 & 0.11 & 0.01 & 0.08 \\
\hline
\end{tabular}

PTH: parathyroid hormone; BMI: body mass index; Ca: serum calcium; Cr: creatinine; 25 (OH) D: 25-hydroxyvitamin D; AKP: alkaline phosphatase. Data are presented as $r$ : ${ }^{\mathrm{a}} p<0.0001,{ }^{\mathrm{b}} p<0.01$, and ${ }^{\mathrm{c}} p<0.05$.

The mechanisms of these distinct differences between the two cities remain unknown. One possibility is that PHPT patients in the USA were diagnosed at the asymptomatic stage, since most people in the USA receive annual physical examinations $[1,2]$. In China, most PHPT patients were diagnosed when they came to hospital due to kidney stones, skeletal lesions, or other symptoms related to hypercalcemia. The duration of PHPT in China is about one year shorter than that in the USA as reported by Liu et al. [6]. The duration of PHPT from the two cities has no significant difference in our current study. The wide use of multichannel chemistry screening tests in China recently may be responsible for the discrepancy.

Another possibility is the nutritional and environmental differences between New Brunswick and Changsha. The lower $25(\mathrm{OH})$ D levels in Chinese patients may reflect low vitamin D intake or less sun exposure [7,8]. Although serum $25(\mathrm{OH})$ D levels are higher $(14.2 \mathrm{ng} / \mathrm{mL})$ than those in cohorts from Shanghai $(13 \mathrm{ng} / \mathrm{mL})$ and Beijing $(8.8 \mathrm{ng} / \mathrm{mL})$, the levels are still much lower than those in patients from New Brunswick (28.0 ng/mL). Our data also show that iPTH levels were much higher and better correlated with calcium in PHPT patients from Changsha. It is consistent with previous studies showing that lower $25(\mathrm{OH})$ D levels and higher iPTH levels are usually associated with more severe PHPT profiles [9, 10]. Higher iPTH might also inhibit liver vitamin D-binding protein production and further lower total 25 $(\mathrm{OH}) \mathrm{D}$ levels [11]. We hypothesize that long-term low 25
$(\mathrm{OH})$ D levels might induce parathyroid gland hyperplasia and subsequent development of adenoma. A previous study found a significant inverse relationship between serum 25 $(\mathrm{OH}) \mathrm{D}$ and gland weight, which indicated that lower 25 $(\mathrm{OH}) \mathrm{D}$ levels are usually associated with heavier parathyroid gland weight, usually leading to severe PHPT [12]. Saliba et al. reported that the sufficient threshold of the prevention of secondary hyperparathyroidism in persons with normal renal function is $25(\mathrm{OH}) \mathrm{D}>20 \mathrm{ng} / \mathrm{mL}$ [13]. Long-term vitamin D deficiency can also mask hypercalcemia and delay the diagnosis of PHPT. It is reasonable to measure $25(\mathrm{OH}) \mathrm{D}$ levels and treat low $25(\mathrm{OH})$ D levels in all patients with elevated PTH level [14].

We also find a difference in the pathology between these two groups of PHPT patients for the first time. Around 92\% of PHPT patients who had surgery in Changsha were found to have parathyroid adenoma, which is twice as many as those in New Brunswick $(p<0.01)$. Most of the PHPT patients in the US are postmenopausal women, and US PHPT patients are also heavier with higher fasting glucose levels, which may also reflect different genetic backgrounds between the two groups of patients as well as different genetically determined PTH metabolism [15]. The higher percentage of parathyroid hyperplasia might be due to selection bias. This study cannot therefore be generalized for all PHPT patients in New Jersey or US. Further studies including better classifications, specific biochemical marker, and transcriptional patterns for adenoma or hyperplasia are needed. 
Low bone mineral density and higher AKP levels suggest that Chinese PHPT patients might have more severe bone disease than those in the USA. In our present study, BMD is lower in both the lumbar spine and hip regions, while the previous Shanghai cohort only showed significantly lower $\mathrm{BMD}$ in the lumbar spine region [6]. Our data suggest that different living conditions and geographic regions may also affect clinical features of PHPT patients [16]. A greater percentage of male patients with PHPT have more kidney stones than female patients. We suggest that female PHPT patients might be more sensitive to bone loss and that male patients might be more likely to develop renal disease. This finding is consistent with a previous study conducted by De Lucia et al. [17]. The PTH level may also have different influences on bone metabolism and metabolic syndrome among different ethnicities and genders [18].

Another interesting finding is that there are more male and premenopausal female PHPT patients from Changsha than from Western countries. This finding is consistent with previous studies in Chinese and Indian PHPT patients $[3,6,19]$. Our data showed similarities between male and premenopausal female PHPT patients which is consistent with the recent study by Castellano et al. [20]. The PHPT patients from Changsha are also younger at diagnosis with much higher iPTH levels and more renal stones, pointing to a possible genetic impact on the presentation of PHPT. Compared to Caucasian and Asian PHPT patients, African American patients presented a more severe PHPT profile, which supports this point [4].

The potential limitation of the current study is that all patients are from two regional referral centers in China and the USA, leading to possible selection bias. We do not have X-ray, ultrasound, or CT scans for asymptomatic kidney stones, so the true prevalence of kidney stones may be different.

\section{Conclusions}

PHPT patients from Changsha present with more severe PHPT profiles and more kidney stones at their initial evaluation. A further study in a larger cohort is warranted to confirm our findings and to explore the underlying mechanisms.

\section{Data Availability}

The data used to support the findings of this study are available from the corresponding author upon request.

\section{Disclosure}

Part of the data was presented as a conference abstract for the Ninth China Youth Association Academic Conference on May 25-27, 2017, Guangdong, Guangzhou, China.

\section{Conflicts of Interest}

Lingqiong Meng, Shuying Liu, Aseel Al-Dayyeni, Zhifeng Sheng, Zhiguang Zhou, and Xiangbing Wang declare that they have no conflict of interest.

\section{References}

[1] S. J. Silverberg, B. L. Clarke, M. Peacock et al., "Current issues in the presentation of asymptomatic primary hyperparathyroidism: proceedings of the Fourth International Workshop," The Journal of Clinical Endocrinology and Metabolism, vol. 99, no. 10, pp. 3580-3594, 2014.

[2] S. J. Silverberg, M. D. Walker, and J. P. Bilezikian, “Asymptomatic primary hyperparathyroidism," Journal of Clinical Densitometry, vol. 16, no. 1, pp. 14-21, 2013.

[3] P. V. Pradeep, B. Jayashree, A. Mishra, and S. K. Mishra, "Systematic review of primary hyperparathyroidism in India: the past, present, and the future trends," International Journal of Endocrinology, vol. 2011, Article ID 921814, 7 pages, 2011.

[4] S. Hu, X. Cai, V. Mewani, B. Wong, S. Trooskin, and X. Wang, "Impact of ethnic background on clinical characteristics and cardiovascular risk factors among patients with primary hyperparathyroidism," Endocrine practice, vol. 22, no. 3, pp. 323-327, 2016.

[5] S. Piciucchi, D. Barone, G. Gavelli, A. Dubini, D. Oboldi, and F. Matteuci, "Primary hyperparathyroidism: imaging to pathology," Journal of Clinical Imaging Science, vol. 2, no. 1, p. 59, 2012.

[6] J. M. Liu, N. E. Cusano, B. C. Silva et al., "Primary hyperparathyroidism: a tale of two cities revisited-New York and Shanghai," Bone research, vol. 1, no. 2, pp. 162-169, 2013.

[7] X. Mao, H. Zheng, Z. Liu et al., "Analysis of $25(\mathrm{OH})$ D serum concentrations of hospitalized elderly patients in the Shanghai area," PloS One, vol. 9, no. 3, article e90729, 2014.

[8] J. Chen, C. Yun, Y. He, J. Piao, L. Yang, and X. Yang, "Vitamin D status among the elderly Chinese population: a crosssectional analysis of the 2010-2013 China national nutrition and health survey (CNNHS)," Nutrition Journal, vol. 16, no. 1, p. 3, 2017.

[9] D. Sukumar, N. C. Partridge, X. Wang, and S. A. Shapses, "The high serum monocyte chemoattractant protein-1 in obesity is influenced by high parathyroid hormone and not adiposity," The Journal of Clinical Endocrinology and Metabolism, vol. 96, no. 6, pp. 1852-1858, 2011.

[10] M. D. Walker, E. Cong, J. A. Lee et al., "Vitamin D in primary hyperparathyroidism: effects on clinical, biochemical, and densitometric presentation," The Journal of Clinical Endocrinology and Metabolism, vol. 100, no. 9, pp. 34433451, 2015.

[11] X. Wang, S. A. Shapses, and H. Al-Hraishawi, "Free and bioavailable 25-hydroxyvitamin d levels in patients with primary hyperparathyroidism," Endocrine Practice, vol. 23, no. 1, pp. 66-71, 2017.

[12] D. S. Rao, M. Honasoge, G. W. Divine et al., "Effect of vitamin D nutrition on parathyroid adenoma weight: pathogenetic and clinical implications," The Journal of Clinical Endocrinology and Metabolism, vol. 85, no. 3, pp. 1054-1058, 2000.

[13] W. Saliba, O. Barnett, H. S. Rennert, I. Lavi, and G. Rennert, "The relationship between serum $25(\mathrm{OH}) \mathrm{D}$ and parathyroid hormone levels," The American Journal of Medicine, vol. 124, no. 12, pp. 1165-1170, 2011.

[14] T. Ahsan, U. Erum, K. M. Inam Pal et al., "The many guises of primary hyperparathyroidism: an unchanged scenario," JPMA, vol. 67, no. 4, pp. 580-585, 2017.

[15] R. M. Cisco, J. H. Kuo, L. Ogawa et al., "Impact of race on intraoperative parathyroid hormone kinetics: an analysis of 910 patients undergoing parathyroidectomy for primary 
hyperparathyroidism," Archives of Surgery, vol. 147, no. 11, pp. 1036-1040, 2012.

[16] Ö. Makay, B. Özçınar, T. Şimşek et al., "Regional clinical and biochemical differences among patients with primary hyperparathyroidism," Balkan Medical Journal, vol. 34, no. 1, pp. 28-34, 2017.

[17] F. De Lucia, S. Minisola, E. Romagnoli et al., "Effect of gender and geographic location on the expression of primary hyperparathyroidism," Journal of Endocrinological Investigation, vol. 36, no. 2, pp. 123-126, 2013.

[18] D. Han, S. Trooskin, and X. Wang, "Prevalence of cardiovascular risk factors in male and female patients with primary hyperparathyroidism," Journal of Endocrinological Investigation, vol. 35, no. 6, pp. 548-552, 2012.

[19] S. Jha, M. Jayaraman, A. Jha, R. Jha, K. D. Modi, and J. V. Kelwadee, "Primary hyperparathyroidism: a changing scenario in India," Indian journal of endocrinology and metabolism, vol. 20, no. 1, pp. 80-83, 2016.

[20] E. Castellano, R. Attanasio, A. Boriano et al., "Sex difference in the clinical presentation of primary hyperparathyroidism: influence of menopausal status," The Journal of Clinical Endocrinology and Metabolism, vol. 102, no. 11, pp. 4148-4152, 2017. 


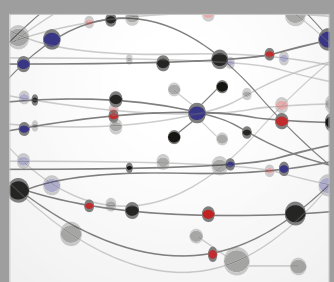

The Scientific World Journal
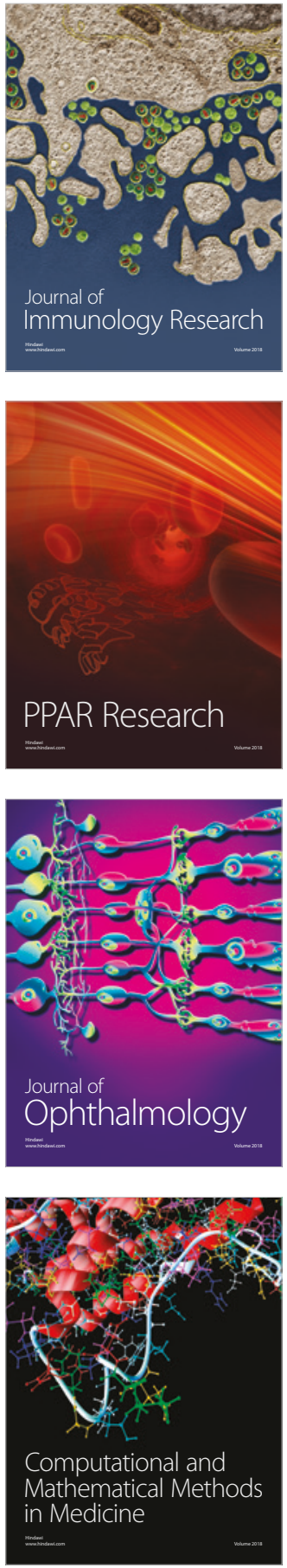

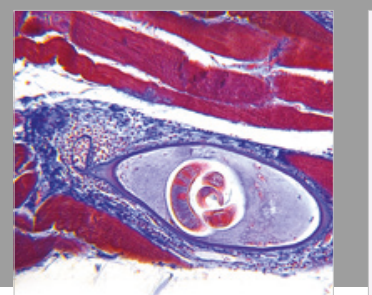

Gastroenterology Research and Practice

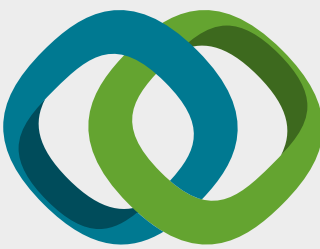

\section{Hindawi}

Submit your manuscripts at

www.hindawi.com
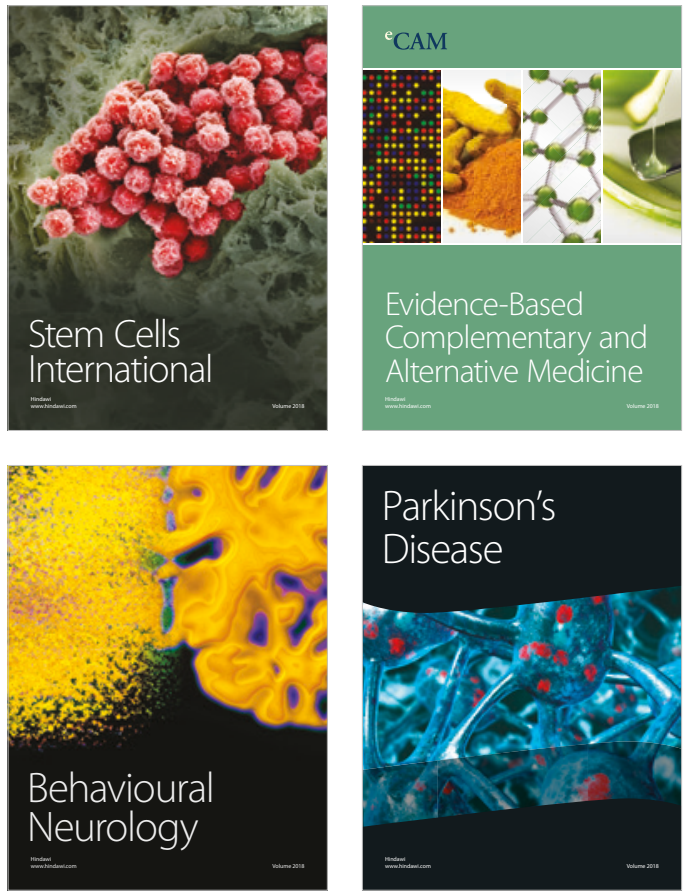

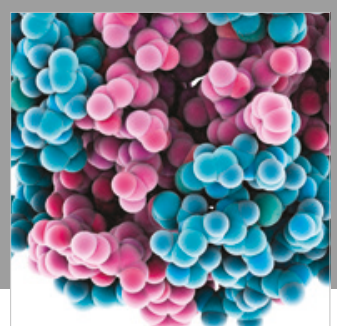

ournal of

Diabetes Research

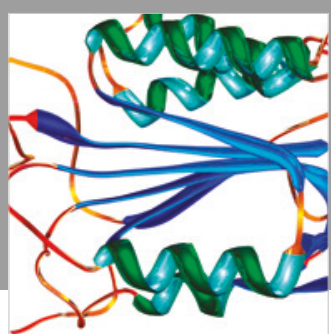

Disease Markers
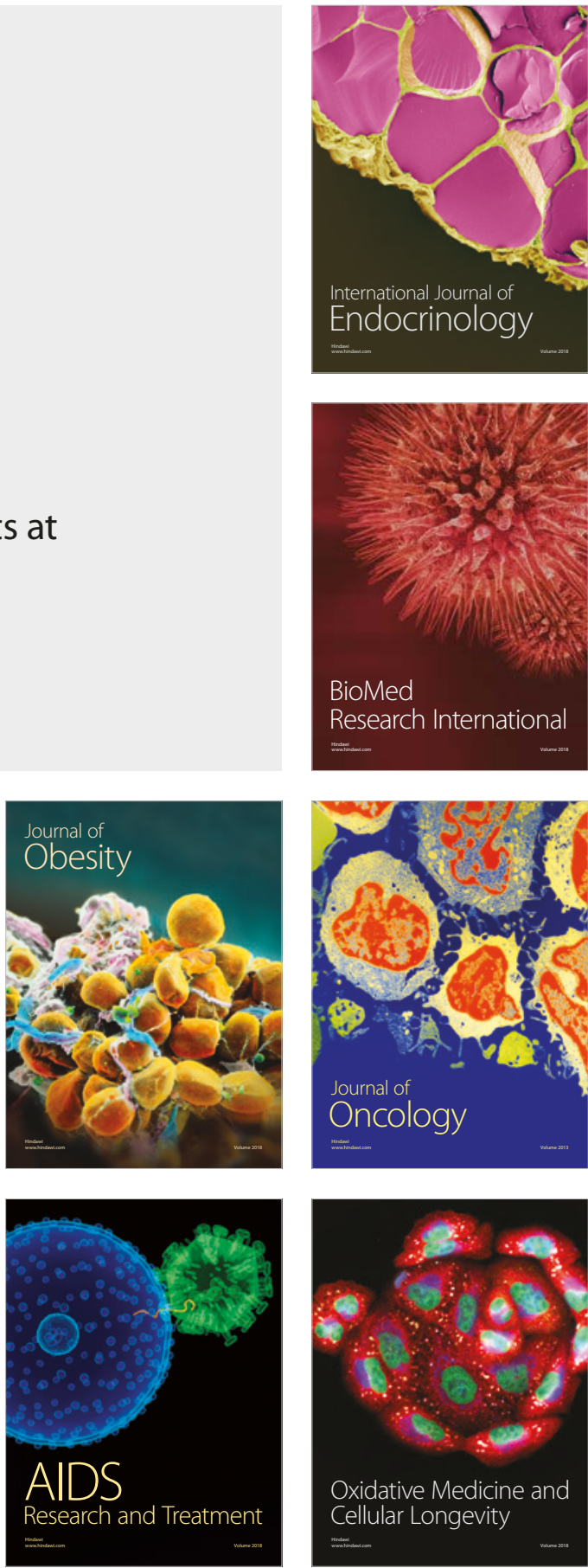